\title{
PENGARUH PEMBELAJARAN DENGAN TEKNIK QUICK ON THE DRAW TERHADAP HASIL BELAJAR MATEMATIKA SISWA KELAS VIII SMP
}

\author{
Fitria Rusti Utami ${ }^{1}$, Agus Susanta ${ }^{2}$, Nurul Astuty Yensy ${ }^{3}$ \\ ${ }^{1,3}$ Program Studi Pendidikan Matematika JPMIPA FKIP Universitas Bengkulu \\ ${ }^{2}$ Program Studi S-2 Pendidikan Dasar FKIP Universitas Bengkulu \\ 1 itriarustiutami@gmail.com, ${ }^{2}$ agusunib@yahoo.com, ${ }^{3}$ nurulastutyyensy@yahoo.com
}

\begin{abstract}
ABSTRAK
Penelitian ini mengkaji masalah peningkatan hasil belajar siswa antara siswa yang mendapatkan pembelajaran dengan teknik Quick On The Draw dan pembelajaran konvensional ditinjau dari kemampuan awal matematis siswa dan hasil tes akhir. Penelitian ini merupakan penelitian kuasi eksperimen dengan desain penelitian the nonequivalent posttes-only control group design menggunakan teknik purposive sampling. Populasi dalam penelitian ini adalah siswa kelas VIII SMPN 13 Kota Bengkulu, dengan kelas VIII C sebagai kelas eksperimen dan kelas VIII D sebagai kelas kontrol. Instrumen yang digunakan dalam penelitian ini adalah tes akhir dalam bentuk soal uraian. Berdasarkan hasil observasi, aktivitas siswa dengan menggunakan teknik quick on the draw meningkat. Teknik analisis data dengan menggunakan uji-t dengan $t_{\text {hitung }}=2,03$ dan $t_{\text {tabel }}=1,99$ dengan $\alpha=0,05$. Karena $t_{\text {hitung }}>t_{\text {tabel }}$ maka disimpulkan bahwa hasil belajar matematika siswa dengan menggunakan teknik quick on the draw lebih baik dari pembelajaran konvensional di SMP Negeri 13 Kota Bengkulu.
\end{abstract}

Kata kunci : hasil belajar, teknik quick on the draw, aktivitas siswa

\begin{abstract}
This study examines the problem of improving student learning outcomes between students who are learning with the Quick on The Draw technique and conventional learning in terms of students' final mathematical abilities and final test results. This research is a quasi experimental research with design design of posttest nonequivalent control group using purposive sampling technique. The population in this study were students of class VIII SMPN 13 Kota Bengkulu, with class VIII C as experimental class and class VIII D as control class. The instrument used in this study is the final test in the form of a description problem. Based on the observation, student activity using quick on the draw technique increases. Technique of data analysis by using $t$-test with $t_{\text {count }}=2.03$ and $t_{\text {table }}=1,99$ with $\alpha=0,05$. Because $t_{\text {hitung }}>$ ${ }_{t} t_{\text {abel }}$ then concluded the result of student's mathematics learning by using quick on draw technique better than conventional learning in SMP Negeri 13 Kota Bengkulu.
\end{abstract}

Keywords: learning outcomes, rapid on the draw techniques, student activities

\section{PENDAHULUAN}

Pendidikan merupakan bagian yang terpenting dalam kehidupan manusia. Melalui pendidikan, siswa memiliki kemampuan untuk mengembangkan pengetahuan, keterampilan, dan mampu bersaing sehingga menjadi sumber daya manusia yang berkualitas. Pendidikan yang tidak hanya mempersiapkan para siswanya untuk mencapai suatu profesi dan jabatan, tetapi untuk menyelesaikan masalahmasalah yang dihadapinya dalam kehidupan sehari-hari. Salah satu pendidikan tersebut adalah pendidikan matematika.

Pendidikan matematika merupakan salah satu pendidikan dasar dalam bidang pengajaran. Menurut Ali \& Muhlisrarini (2014 : 57) menyatakan bahwa pendidikan 
matematika merupakan upaya untuk meningkatkan daya nalar siswa, meningkatkan kecerdasan peserta didik dengan tahap pembelajaran yang berkaitan antara satu tahap dengan tahap lainnya. Pembelajaran matematika melatih siswa untuk mencapai sebuah target penyelesaian yang tidak hanya memiliki tujuan untuk mendapatkan hasil semata, tetapi pembelajaran matematika menuntut siswa untuk menyelesaikan semua proses langkah penyelesaian.

Pembelajaran yang diberikan guru masih sering menggunakan pembelajaran yang bersifat teacher-centered, padahal menurut Trianto (dalam Suryadinata, 2015: 10), pada pembelajaran teacher-centered siswa tidak memiliki strategi belajar untuk memahami pembelajaran, berpikir, dan memotivasi diri sendiri. Pembelajaran teacher-centered menjadikan siswa lebih terlatih untuk mengerjakan soal rutin (drill exercise) dan menggunakan rumus sehngga siswa dilatih mengerjakan soal yang prosedural. Masalah ini banyak dijumpai dalam kegiatan proses belajar mengajar di kelas.

Berdasarkan pengamatan yang dilakukan pada SMPN 13 Kota Bengkulu, metode belajar yang digunakan dalam pemahaman materi siswa yang kurang bervariasi menyebabkan siswa kurang memahami materi. Hal ini dibuktikan dengan $70 \%$ hasil belajar siswa kelas VIII SMP Negeri 13 Kota Bengkulu belum mencapai KKM dengan standar KKM 75. Berdasarkan hasil belajar tersebut, dapat disimpulkan bahwa hasil belajar kelas VIII SMP Negeri 13 Kota Bengkulu masih belum baik.

Salah satu langkah yang dapat dilakukan untuk meningkatkan hasil belajar siswa adalah dengan menggunakan pembelajaran aktif. Strategi pembelajaran aktif mengharapkan siswa terlibat secara aktif dalam kegiatan pembelajaran untuk berpikir, berinteraksi, mencoba, menemukan konsep baru atau menghasilkan suatu karya. Untuk itu terdapat karakteristik dalam pembelajaran aktif sebagaimana yang dikemukakan dalam panduan pembelajaran model ALIS (dalam Uno dan Mohamad, 2014: 75). Dengan pembelajaran aktif, Ruseffendi (2006: 285) mengatakan bahwa siswa dapat mengingat apa yang dipelajari lebih lama, dan pengetahuan menjadi lebih luas hal ini dikarenakan siswa aktif dalam menggali informasi yang ada, dan memiki pengalaman sendiri dalam memahami materi tersebut sehingga pengalaman dalam proses pembelajaran lebih diingat oleh siswa.

Salah satu pembelajaan aktif adalah dengan teknik quick on the draw. Menurut Ginnis (2008:163), quick on the draw menekankan untuk bekerja dalam tim. Dengan adanya teknik quick on the draw membantu siswa untuk membiasakan diri mendasarkan belajar pada sumber, bukan guru. Dalam proses pembelajaran dengan menggunakan teknik quick on the draw, digunakan handout sebagai bahan belajar. Dengan menggunakan handout tersebut, siswa dapat memahami materi secara mandiri..

Adapun langkah dalam pelaksanaan quick on the draw menurut Ginnis (2008: 164) sebagai berikut : (1) Siapkan satu set pertanyaan; (2) Bagi kelas ke dalam kelompokkelompok kecil. Beri warna untuk tiap kelompok; (3) Tiap siswa dalam tiap kelompok diberi materi bisa berupa halaman tertentu dari buku teks yang biasanya; (4) Pada kata "mulai", satu orang (orang pertama) dari tiap kelompok berjalan ke meja guru, mengambil pertanyaan pertama menurut warna mereka dan kembali membawanya ke kelompok; (5) Kelompok tersebut berdiskusi mencari jawaban pertanyaan dan kemudian jawaban ditulis di lembar kertas terpisah; (6) Setelah selesai, jawaban diberikan kepada guru oleh orang kedua. Jika jawaban akurat dan lengkap, pertanyaan kedua dari tumpukan warna mereka dapat diambil. Begitu seterusnya; (7) Kelompok yang menang adalah yang pertama menjawab semua pertanyaan; (8) Guru bersama siswa menjawab semua pertanyaan dan siswa membuat catatan tertulis.

Berdasarkan permasalahan yang ditemukan, telah dilakukan penelitian yang berjudul "Pengaruh Pembelajaran dengan Teknik Quick On The Draw Terhadap Hasil Belajar Siswa Kelas VIII SMP Negeri 13 Kota Bengkulu". Tujuan dari penelitian ini adalah untuk mengetahui ada atau tidak pengaruh yang signifikan teknik quick on the draw terhadap 
hasil belajar siswa kelas VIII SMP Negeri 13 Kota Bengkulu.

\section{METODE}

Jenis penelitian adalah penelitian eksperimen semu dengan pemilihan sampel menggunakan teknik perposive sampling. Penelitian ini dilakukan di SMPN 13 Kota Bengkulu. Populasi dalam penelitian ini adalah seluruh siswa kelas VIII SMPN 13 Kota Bengkulu tahun ajaran 2016/2017. Desain penelitian yang digunakan dalam penelitian ini adalah dengan desain the nonequivalent posttest-only control design sesuai pada tabel berikut:

Tabel 1 Desain Penelitian

\begin{tabular}{|c|cc|}
\hline Kelas & Perlakuan & Posttes \\
\hline Eksperimen & $\mathbf{X}$ & $\mathrm{O}_{1}$ \\
\hline Kontrol & $\mathbf{Y}$ & $\mathrm{O}_{2}$ \\
\hline
\end{tabular}

Sampel ditentukan berdasarkan hasil ulangan matematika siswa kelas VIII pada materi Garis Singgung Lingkaran, kemudian data kemampuan awal siswa dilakukan uji kesamaan varians data awal dengan menggunakan uji-F. Berdasarkan hasil pengujian, disimpulkan kelas VIIIC dan VIIID memiliki varians yang sama sehingga kelas VIII C dapat digunakan sebagai kelas eksperimen dan kelas VIII D sebagai kelas kontrol.

Dalam penelitian eksperimen, terdapat dua variabel yang menjadi perhatian utama, yaitu variabel bebas dan variabel terikat (Sudjana dan Ibrahim, 1989: 19). Variabel bebas dalam penelitian ini adalah teknik quick on the draw dan pembelajaran konvensional. Variabel terikat dalam penelitian ini adalah hasil belajar siswa. Instrumen penelitian adalah soal tes akhir. Uji coba yang dilakukan pada kelas uji coba digunakan untuk menguji kevalidan soal, uji reliablitas soal, uji tingkat kesukaran soal dan uji daya pembeda soal.

Uji validitas dalam penelitian ini menggunakan uji korelasi product moment angka kasar, yaitu:

$$
r_{x y}=\frac{N \sum X Y-\left(\sum X\right)\left(\sum Y\right)}{\sqrt{\left\{N X^{2}-\left(\sum X\right)^{2}\right\}\left\{N Y^{2}-\left(\sum Y\right)^{2}\right\}}}
$$

(Arikunto, 2010: 213)
Soal dinyatakan valid apabila $r_{\text {hitung }} \geq r_{\text {tabel. }}$ Suatu instrumen dikatakan reliabel jika insrumen tersebut konsisten untuk setiap ukurannya sehingga dapat dipercaya.Untuk menguji reliabilitas tes hasil belajar digunakan rumus alpha sebagai berikut.

$$
r_{11}=\left(\frac{n}{n-1}\right)\left(1-\frac{\sum S_{1}{ }^{2}}{S_{1}{ }^{2}}\right)
$$

(Sudijono, 2011: 208)

Daya pembeda soal menggunakan formulasi sebagai berikut:

$$
D P=\frac{\overline{X_{A}}-\overline{X_{B}}}{S M I}
$$

(Lestari \& Yudhanegara, 2015: 219)

Adapun kriteria daya pembeda soal sebagai berikut :

Tabel 2 Kriteria Daya Pembeda

\begin{tabular}{|c|c|}
\hline Daya Pembeda & Evaluasi \\
\hline $0,70 \leq \mathrm{DP}<1,00$ & $\begin{array}{c}\text { Baik } \text { sekali } \\
\text { (Lestari }\end{array}$ \\
\hline $0,40 \leq \mathrm{DP}<0,70$ & Baik \\
\hline $0,20 \leq \mathrm{DP}<0,40$ & Cukup \\
\hline $0,00 \leq \mathrm{DP}<0,20$ & Jelek \\
\hline
\end{tabular}

(Arikunto, 2009: 209)

Uji tingkat kesukaran soal menggunakan rumus sebagai berikut.

$$
T K=\frac{\bar{X}}{S M I}
$$

(Lestari \& Yudhanegara 2015: 224)

Kriteria tingkat kesukaran soal adalah sebagai berikut :

Tabel 3 Kriteria Tingkat Kesukaran Soal

\begin{tabular}{|c|c|}
\hline $\begin{array}{c}\text { Indeks } \\
\text { kesukaran }\end{array}$ & Klasifikasi \\
\hline $0,00 \leq \mathrm{TK}<0,30$ & Soal sukar \\
\hline $0,30 \leq \mathrm{TK}<0,70$ & Soal sedang \\
\hline $0,70 \leq \mathrm{TK} \leq 1,00$ & Soal mudah \\
\hline \multicolumn{2}{|c|}{ (Arikunto, 2009: 210 ) }
\end{tabular}

(Arikunto, 2009: 210)

Tes akhir yang diberikan kepada siswa akan dilakukan uji analisis data, yaitu uji normalitas, uji homogenitas, dan uji hipotesis. Uji normalitas digunakan untuk mengetahui apakah sebaran data berdistribusi normal atau tidak (Lestari \& Yudhanegara, 2015: 243).Uji normalitas yang digunakan dalam penelitian ini menggunakan software SPSS dengan menggunakan uji Kolmogorov-Smirnov dan nilai Skewness.Dengan kriteria jika sig $>0,05$ 
maka $\mathrm{H}_{0}$ diterima. Jka $-2<$ nilai Skewness $<2$ maka $\mathrm{H}_{0}$ diterima.

Uji homogenitas digunakan untuk membuktikan bahwa sampel berasal dari populasi yang homogen. Untuk menguji homogen atau tidak penelitian ini, digunakan uji Fisher sebagai berikut:

$$
F=\frac{\text { Varians terbesar }}{\text { Varians terkecil }}
$$

Jika $x_{\text {hitung }}^{2} \leq x_{\text {tabel }}^{2}$ maka varians sampel homogen. Taraf signifikan yang digunakan adalah $5 \%$ dan $\mathrm{v}_{1}=\mathrm{N}-1, \mathrm{v}_{2}=\mathrm{N}-1$. Jika syarat normalitas dan homogenitas terpenuhi, maka dilakukan uji hipotesis. Pengujian hipotesis menggunakan uji dua pihak. Dengan kriteria pengujian sebagai berikut:

$\mathrm{H}_{0} \quad$ : Tidak adanya pengaruh pembelajaran yang signifikan dengan teknik quick on the draw terhadap kemampuan pemahaman konsep siswa kelas VIII SMP Negeri 13 Kota Bengkulu

$\mathrm{H}_{1} \quad$ : Adanya pengaruh pembelajaran yang signifikan dengan teknik quick on the draw terhadap kemampuan pemahaman konsep siswa kelas VIII SMP Negeri 13 Kota Bengkulu

Rumus uji hipotesis yang digunakan adalah korelasi product moment sebagai berikut.

$$
t=\frac{\bar{X}_{1}-\bar{X}_{2}}{\sqrt{\frac{s_{1}{ }^{2}}{n_{1}}+\frac{s_{2}{ }^{2}}{n_{2}}}}
$$

Sugiyono (2012: 138)

Kriteria pengujian jika $t_{\text {hitung }} \leq \mathrm{t}_{\text {tabel }}$ dengan $\alpha=0,05$ maka $\mathrm{H}_{0}$ diterima.

\section{HASIL DAN PEMBAHASAN}

Penelitian ini dilaksanakan pada tanggal 22 April - 31 Mei 2017 di SMP Negeri 13 Kota Bengkulu. Sebelum tes diberikan kepada kedua kelas sampel, tes terlebih dahulu di uji validasi. Soal tes akhir diuji validitas oleh validator ahli kemudian diuji cobakan terlebih dahulu di kelas uji coba yaitu kelas VIIIE SMPN 13 Kota Bengkulu yang diikuti oleh 28 siswa. Berdasarkan hasil uji instrimen, dapat disimpulkan sebagai berikut:
Tabel 4 Uji Instrimen Penelitian

\begin{tabular}{|c|c|c|c|}
\hline $\begin{array}{c}\text { No } \\
\text { Soal }\end{array}$ & $\begin{array}{c}\text { Uji } \\
\text { Validitas }\end{array}$ & $\begin{array}{c}\text { Uji } \\
\text { Tingkat } \\
\text { Kesukaran } \\
\text { Soal }\end{array}$ & $\begin{array}{c}\text { Uji Daya } \\
\text { Pembeda }\end{array}$ \\
\hline 1 & Valid & $\begin{array}{l}\text { TK } \\
\text { Sedang }\end{array}$ & Cukup \\
\hline 2 & Valid & $\begin{array}{l}\text { TK } \\
\text { Sedang }\end{array}$ & Cukup \\
\hline 3 & Valid & $\begin{array}{l}\text { TK } \\
\text { Sedang }\end{array}$ & Cukup \\
\hline 4 & Tidak & $\begin{array}{l}\text { TK } \\
\text { Sedang }\end{array}$ & Buruk \\
\hline 5 & Valid & $\begin{array}{l}\text { TK } \\
\text { Sedang }\end{array}$ & Cukup \\
\hline 6 & Valid & $\begin{array}{l}\text { TK } \\
\text { Sedang }\end{array}$ & Cukup \\
\hline 7 & Valid & $\begin{array}{l}\text { TK } \\
\text { Sedang }\end{array}$ & Baik \\
\hline
\end{tabular}

Berdasarkan tabel 4, hasil perhitungan uji validitas soal yang terdiri dari 7 soal esay diperoleh 6 soal dinyatakan valid dan 1 soal dinyatakan tidak valid. Hasil perhitungan uji tingkat kesukaran soal diperoleh bahwa 7 soal yang diuji memiliki kriteria tingkat kesukaran sedang $(0,30 \leq p<$ 0,70). Berdasarkan hasil analisis uji validitas, uji tingkat kesukaran soal, dan uji daya pembeda dapat disimpulkan soal yang dapat digunakan adalah soal 1, 2, 3, 5, 6, dan 7 sedangkan soal 4 tidak digunakan karena soal tersebut tidak valid dan daya pembeda pada soal 4 buruk. Jadi soal yang digunakan untuk tes akhir sebanyak 6 soal.

Reliabilitas instrumen dihitung menggunakan rumus alpha. Nilai $r_{11}$ dengan $\mathrm{N}=28$ dan taraf signifikan $5 \%$, jika $\mathrm{r}_{11} \geq$ 0,70 berarti tes yang sedang diuji reliabilitasnya dinyatakan telah memiliki reliabilitas yang tinggi (reliabel).

Berdasarkan perhitungan $r_{11}$ didapatkan bahwa instrumen soal memiliki reliabilitas tinggi karena $r_{11}=0,768946>0,070$.

Uji normalitas data digunakan software SPSS dengan ketentuan jika sig > 0,05 maka data berdistribusi normal. Berikut hasil uji normalitas data: 
Tabel 5 Uji Normalitas

\begin{tabular}{|c|c|c|c|}
\hline Kelas & Sig & Kriteria & Keterangan \\
\hline Kontrol & 0,2 & 0,05 & $\begin{array}{c}\text { Berdistribusi } \\
\text { normal }\end{array}$ \\
\hline Eksperimen & 0,07 & 0,05 & $\begin{array}{c}\text { Berdistribusi } \\
\text { normal }\end{array}$ \\
\hline
\end{tabular}

Berdasarkan tabel 5, p-sig pada kelas kontrol $=0,2$ dan $\mathrm{p}$-sig pada kelas eksperimen $=0,07$ dengan sig $>0,05$ maka dapat dsimpulkan bahwa data berdistribusi normal.

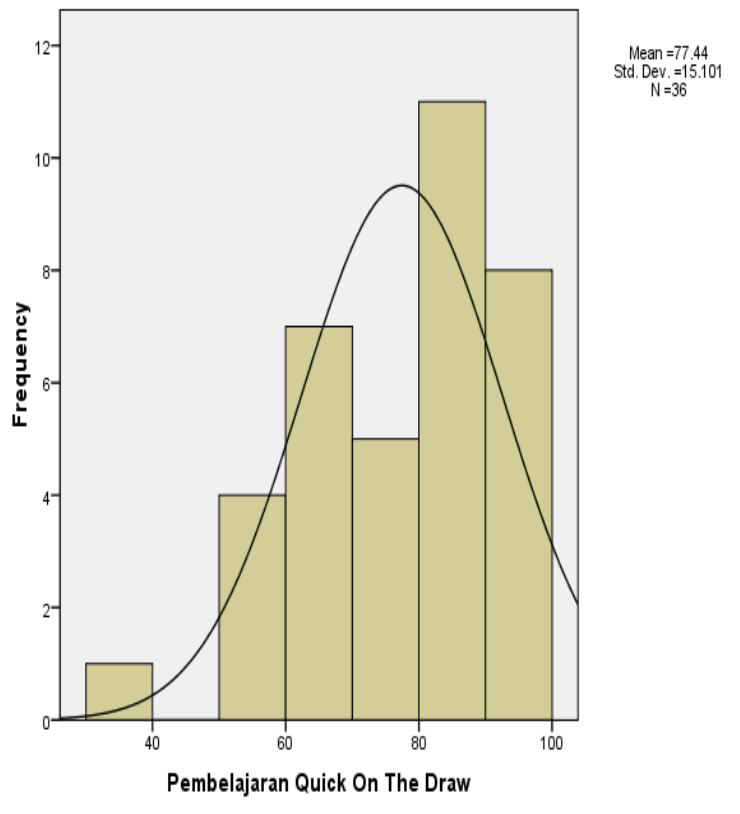

Gambar 1 Kurva Normalitas Kelas Eksperimen

Gambar 1 menunjukkan bahwa data pada kelas eksperimen dengan teknik quick on the draw berdistribusi normal. Hal ini terlihat bahwa kurva tersebut membentuk lonceng.

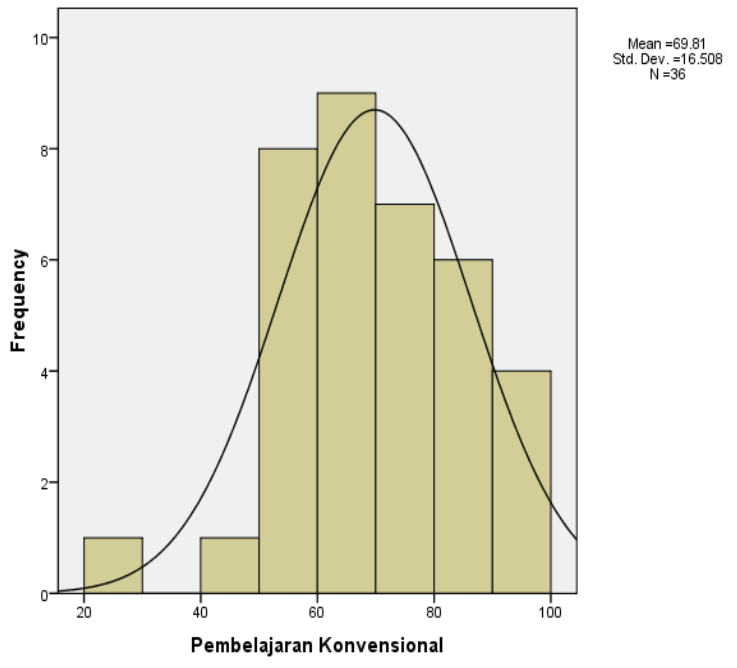

Gambar 2 Kurva Normalitas Kelas Kontrol
Gambar 2 merupakan kurva normalitas pada kelas kontrol, terlihat kurva skewness membentuk lonceng. Karena kurva tersebut membentuk lonceng, maka data kelas dengan pembelajaran konvensional berdistribusi normal.

Sedangkan perhitungan uji homogenitas menggunakan uji-F dengan ketentuan $\mathrm{F}_{\text {hitung }}<$ $F_{\text {tabel }}$ maka data homogen. Dengan taraf nyata $(\alpha)=5 \%, v_{1}=\mathrm{N}-1=36-1=35, \mathrm{v}_{2}=\mathrm{N}-1=$ $36-1=35$ sehingga $\mathrm{F}_{\text {tabel }}=\mathrm{F}_{(0,05)(35: 35)}=1,76$. Karena $\mathrm{F}_{\text {hitung }}=1,18<\mathrm{F}_{\text {tabel }}=1,76$, maka keda sampel homogen. Setelah uji prasyarat analisis, untuk menjawab hipotesis digunakan uji-t sebagai berikut:

Tabel 6 Uji Hipotesis

\begin{tabular}{|c|c|c|}
\hline $\mathbf{t}_{\text {hitung }}$ & $\mathbf{t}_{\text {tabel }}$ & Keterangan \\
\hline 2,03 & 1,99 & $\mathrm{H}_{0}$ ditolak \\
\hline
\end{tabular}

Berdasarkan tabel 6 uji hipotesis dengan menggunakan uji-t diperoleh $t_{\text {hitung }}>t_{\text {tabel }}$, maka $\mathrm{H}_{0}$ ditolak, sehingga dapat disimpulkan terdapat pengaruh yang signifikan pembelajaran dengan teknik quick on the draw terhadap hasil belajar siswa kelas VIII SMP Negeri 13 Kota Bengkulu.

Hasil perhitungan hipotesis menyatakan bahwa terdapat pengaruh yang signifikan pembelajaran dengan teknik quick on the draw terhadap hasil belajar siswa kelas VIII SMP Negeri 13 Kota Bengkulu. Berikut tabel persentase hasil tes akhir per butir soal:

Tabel 7 Persentase Hasil Tes Akhir Per Butir Soal

\begin{tabular}{|c|c|c|c|c|c|}
\hline $\begin{array}{c}\text { No } \\
\text { Soal }\end{array}$ & $\begin{array}{c}\text { Skor } \\
\text { Maks }\end{array}$ & \multicolumn{2}{c|}{$\begin{array}{c}\text { Kelas } \\
\text { Eksperimen }\end{array}$} & \multicolumn{2}{c|}{$\begin{array}{c}\text { Kelas } \\
\text { Kontrol }\end{array}$} \\
\cline { 2 - 6 } & $\begin{array}{c}\text { Rata- } \\
\text { rata }\end{array}$ & $\%$ & $\begin{array}{c}\text { Rata- } \\
\text { rata }\end{array}$ & $\%$ \\
\hline 1 & 8 & 6,00 & $75 \%$ & 4,94 & $62 \%$ \\
\hline 2 & 6 & 3,33 & $56 \%$ & 5,75 & $96 \%$ \\
\hline 3 & 21 & 15,61 & $74 \%$ & 16 & $76 \%$ \\
\hline 4 & 25 & 18,72 & $75 \%$ & 19,94 & $80 \%$ \\
\hline 5 & 22 & 18,61 & $85 \%$ & 13,47 & $61 \%$ \\
\hline 6 & 25 & 20,78 & $83 \%$ & 15,06 & $60 \%$ \\
\hline \multicolumn{3}{|c|}{ Berdasarkan tabel 7 memperlihatkan } \\
\hline
\end{tabular}

bahwa kelas kontrol memperoleh capaian lebih baik pada soal no 2, 3, dan 4. Capaian $96 \%$ di kelas kontrol untuk soal no. 2 bermakna ratarata kelas kontrol 5,75 dari skor maksimal 6 . Soal no 2 merupakan soal untuk menentukan jaring-jaring kubus atau balok yang benar. Pada 
soal no 2 merupakan soal pada materi pertama, sehingga dalam proses pembelajaran yang berlangsung siswa belum terbiasa dengan teknik quick on the draw sehingga siswa kurang memahami jaring-jaring dengan baik. Sedangkan pada kelas kontrol, guru menjelaskan dengan rinci langkah dalam menyelidiki jaring-jaring kubus dan balok.

Sedangkan pada soal nomor 3 di kelas eksperimen, siswa banyak melakukan kesalahan dalam menggambarkan balok dengan ukuran yang sesuai. Terdapat 16 siswa yang menjawab dengan ukuran yang tidak sesuai dan 6 siswa yang tidak menggambarkan balok. Selain itu siswa juga tidak mengerjakan soal dengan langkah penyelesaian masalah yang runtun. Sedangkan pada kelas kontrol terdapat 15 siswa yang menjawab dengan ukuran yang tidak sesuai dan 5 siswa yang tidak menjawab.Berikut contoh jawaban siswa pada tes hasil belajar siswa pada kelas eksperimen dan kelas kontrol:

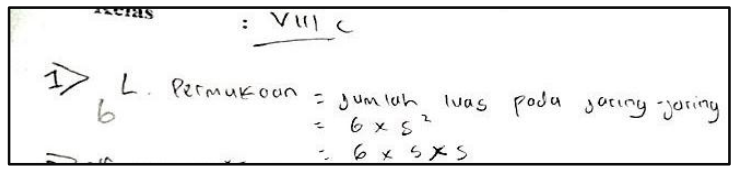

Gambar 3 Jawaban Siswa Kelas EksperimenSoal No 1

Pada nomor 1 didapatkan bahwa semua siswa dapat mengerjakan soal dengan benar. Siswa mampu menentukan luas dari permukaan kubus berdasarkan gambar jaring-jaring tersebut.

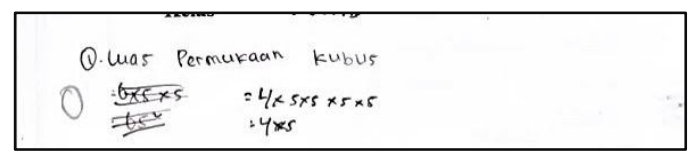

Gambar 4 Jawaban Siswa Kelas KontrolSoal No 1

Berdasarkan jawaban siswa pada gambar 4, siswa keliru dalam menentukan rumus luas permukaan kubus berdasarkan jaring-jaringnya. Pada gambar 2 siswa menuliskan Luas permukaan $=4 \times \mathrm{s} \times \mathrm{s}$, sedangkan jawaban yang benar adalah Luas permukaan $=6 \times \mathrm{s} \times \mathrm{s}$. Berdasarkan jawaban tersebut, siswa tidak dapat mengetahui luas permukaan tersebut tetapi siswa bekerja sama dalam menjawab soal. Kesalahan tersebut dikarenakan siswa tidak memperhatikan guru menjelaskan mengenai luas permukaan kubus.

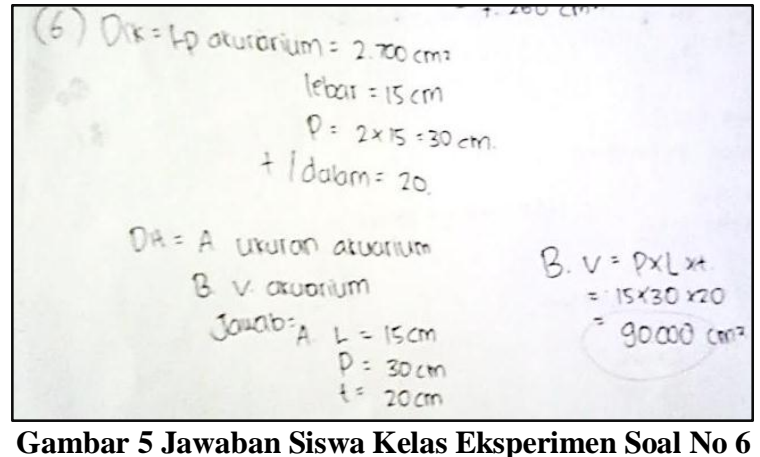

Berdasarkan gambar 5, siswa sudah mengetahui informasi yang terdapat dalam soal yaitu luas permukaan akuarium dengan ukuran lebar $15 \mathrm{~cm}$, panjangnya 2 kali lebar dan kedalaman 5 lebihnya dari lebar akuarium dan informasi yang tidak diketahui yakni ukuran sebenarnya dari akuarium dan volume pada akuarium tersebut, tetapi siswa menulis jawaban tidak sistematis. Terlihat dari lembar jawaban siswa, siswa masih keliru dalam hasil perhitungan hasil perkalian volume pada sal nomor 6(b), siswa menghitung $15 \times 30 \times 20=$ $90.000 \mathrm{~cm}^{2}$ sedangkan jawaban yang benar adalah $15 \times 30 \times 20=9.000 \mathrm{~cm}^{3}$. Pada satuan yang digunakan oleh siswa juga masih keliru karena satuan volume yang ditulis oleh siswa adalah $\mathrm{cm}^{2}$ sedangkan untuk satuan volume yang benar dalam jawaban soal adalah $\mathrm{cm}^{3}$.

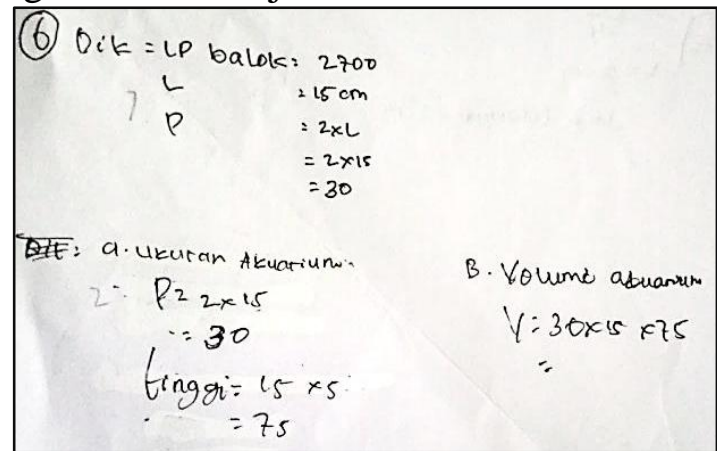

Gambar 6 Jawaban Siswa Kelas Kontrol Soal No 6

Gambar 6 menunjukkan kesalahan

siswa dalam menentukan ukuran akuarium yang berbentuk balok, siswa melakukan kesalahan saat menentukan tinggi akuarium. Pada jawaban yang benar, tinggi akuarium $=$ lebar $+5 \mathrm{~cm}=15 \mathrm{~cm}+5 \mathrm{~cm}=20 \mathrm{~cm}$. Sedangkan siswa menentukan tinggi akuarium $=$ lebar $\times 5 \mathrm{~cm}=15 \mathrm{~cm} \times 5 \mathrm{~cm}=75 \mathrm{~cm}$. Sehingga untuk soal nomor 6 (b) jawaban siswa menjadi keliru. 
Dalam proses pembelajaran pada kelas eksperimen, siswa terlihat sangat aktif dalam proses pembelajaran. Pada proses pembelajaran, siswa banyak bertanya kepada guru apa yang belum dipahami oleh siswa. Amri (2015: 79) mengatakan bahwa, siswa dapat berpikir secara kritis, aktif dan kreatif, serta dengan belajar aktif siswa lebih terdorong mencari informasi, data, dan mencari sendiri jawaban atas pertanyaan. Sejalan dengan itu, Ginnis (2008: 164) menyatakan bahwa teknik quick on the draw mendorong siswa untuk aktif dalam kerja kelompok, kelompok dapat belajar untuk belajar mandiri dalam mengerjakan tugas bukan menduplikasi tugas.

Pada proses pembelajaran kelas eksperimen, guru membagi siswa dalam kelompok heterogen berdasarkan data kemampuan awal matematis siswa dan ditinjau berdasarkan jenis kelamin. Setelah proses pembagian kelompok telah selesai, guru membagikan handout kepada siswa. Siswa banyak bertanya pada pemahaman handout, terutama pada contoh soal. Setelah itu siswa mengambil kartu soal. Pada saat mengerjakan kartu soal,siswa secara aktif dalam berkelompok saling menyampaikan pendapatnya, tetapi masih terdapat kelompok yang bekerja secara individu misalnya kelompok 7. Terutama pada saat mengerjakan kartu soal, siswa terlihat sangat bersaing untuk menyelesaikan karu soal dan menjadi pemenang. Jika terdapat kelompok yang telah menyelesaikan kartu soal, dan guru menyatakan jawaban benar maka kelompok lain akan terpacu untuk menyelesaikan kartu soal juga.Sehingga siswa memiliki motivasi dalam mengerjakan kartu soal. Setelah mengerjakan kartu soal, guru meminta siswa untuk mengerjakan kartu soal di papan tulis yang dipilih secara acak untuk mengerjakannya dan menjelaskan kepada kelompok yang lain mengenai pembahasan kartu soal
tersebut.Berikut merupakan contoh gambar kartu soal pada pertemuan ketiga pada soal nomor 4.

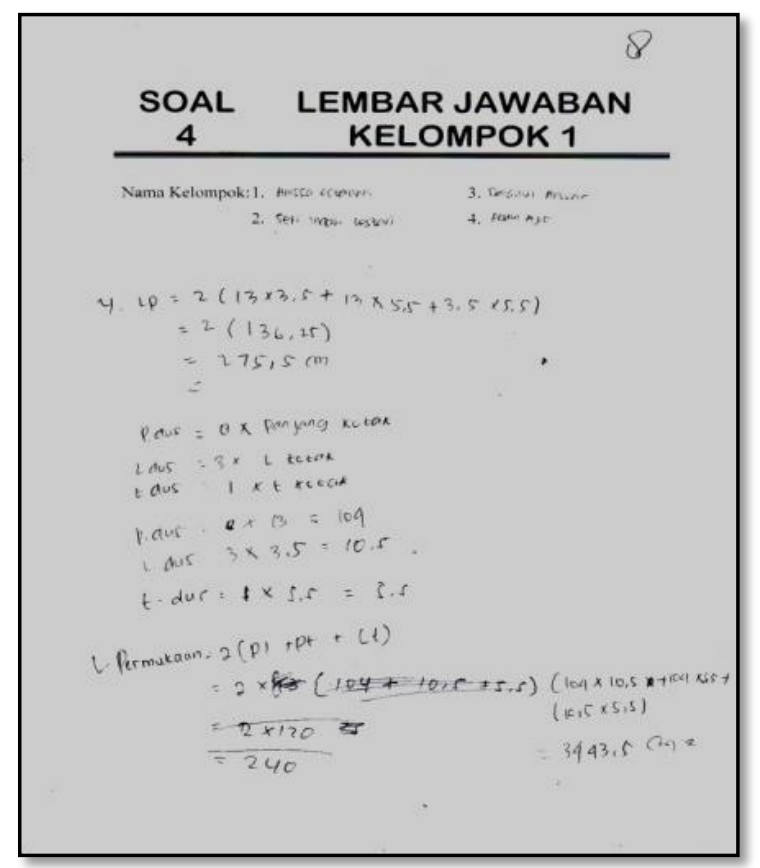

\section{Gambar 7 Lembar Jawaban Pertemuan 3}

Pada gambar 7 merupakan lembar jawaban siswa untuk pertemuan ke-3. Pada jawaban tersebut, kelompok siswa awalnya keliru dalam perhitungan luas permukaan balok. Setelah jawaban siswa dinyatakan salah, siswa mengambil lembar jawaban untuk diperbaiki lalu siswa mengetahui kesalahan dalam jawabannya, kemudian siswa menyerahkan lagi jawaban yang telah diperbaiki.

Sedangkan pada pembelajaran konvensional, guru lebih banyak menjelaskan konsep-konsep. Pembelajaran konvensional merupakan pembelajaran yang didominasi oleh guru sehingga siswa menerima informasi secara pasif. Peneliti mengajar menggunakan pembelajaran konvensional siswa cenderung pasif, hanya ada beberapa siswa yang berperan aktif, yaitu bertanya dan menjawab pertanyaan yang diajukan peneliti. Kendala yang dihadapi oleh peneliti pada pertemuan ini adalah karena terdapat beberapa siswa yang keluar masuk kelas pada saat proses pembelajaran. 


\section{PENUTUP}

\section{Kesimpulan}

Berdasarkan uraian diatas terlihat bahwa hasil belajar siswa yang menggunakan teknik quick on the draw lebih baik daripada hasil belajar siswa siswa yang menggunakan pembelajaran konvensional yang ditunjukkan dengan uji hipotesis dengan $t_{\text {hitung }}=2,03>t_{\text {tabel }}=1,99$, maka dapat disimpulkan bahwa $\mathrm{H}_{0}$ ditolak dan $\mathrm{H}_{1}$ diterima. Hasil deskriptif juga membuktikan bahwa rata-rata hasil tes akhir pada kelas eksperimen sebesar 77,83 dengan presentase ketuntasan siswa sebesar 58,33\% sedangkan rata-rata hasil tes akhir pada kelas kontrol sebesar 70,25 dengan persentase ketuntasan siswa $41,67 \%$. Sehingga disimpulkan hasil belajar siswa pada kelas yang menggunakan teknik quick on the draw lebih baik dari kelas dengan pembelajaran konvensional. Ini berarti terdapat pengaruh yang signifikanhasil belajar matematika siswa yang menggunakan teknik quick on the draw lebih baik dari pada yang hasil belajar matematika siswa yang menggunakan pembelajaran konvensional.

\section{Saran}

Berdasarkan hasil penelitian dapat dikemukakan beberapa saran yaitu (1) agar pelaksanaan pembelajaran quick on the draw dapat berlangsung baik sesuai dengan rencana pembelajaran, maka pada saat pengerjaan kartu soal sebaiknya guru membiasakan siswa untuk mengerjakan secara berkelompok bukan secara individual, (2) dalam penyusunan denah kelompok hendaknya tata letak meja kelompok disusun membentuk $U$ agar pelaksanaan pembelajaran quick on the draw berjalan lancar dan efisien (3) sebaiknya perlu pemberian nomor pada setiap kelompok nomor sebagai identitas di setiap meja kelompok dan nomor posisi pada setiap anggota kelompok, dengan tujuan agar tidak terjadi kecurangan pada pelaksanaan Quick On The Draw.

\section{DAFTAR PUSTAKA}

Ali, H., \& Muhlisrarini. 2014. Perencanaan dan Strategi Pembelajaran Matematika. Jakarta: Rajawali.

Amri, Sofan. 2015. Implementasi Pembelajaran Aktif dalam Kurikulum 2013. Jakarta: Prestasi Pustaka.

Arikunto, S. 2010. Prosedur Penelitian Suatu Pendekatan Praktik. Jakarta: Rineka Cipta.

Ginnis, P. 2008. Trik dan Taktik Mengajar: Strategi Meningkatkan Pencapaian Pengajaran di Kelas. Jakarta: Indeks.

Lestari, K. E., \& Yudhanegara, M. R. 2015. Penelitian Pendidikan Matematika. Bandung: Refika Aditama.

Ruseffendi. 2006. Pengantar Kepada Membantu Guru Mengembangkan Kompetensinya dalam Pengajaran Matematika untuk Meningkatkan CBSA. Bandung: Tarsito.

Sudijono, A. 2011. Pengantar Evaluasi Pendidikan. Jakarta: Rajagrafindo.

Sudjana, N, \& Ibrahim. 1989. Penelitian dan Penilaian Pendidikan. Bandung: Sinar Baru.

Suryadinata, Nurain. 2015. Pengembangan Perangkat Pembelajaran Strategi Quick On The Draw Dengan Masalah Open Ended untuk Meningkatkan Kemampuan Berpikir Kreatif Materi Prisma dan Limas. Universitas Muhammadiyah Metro. Volume 4, No.1. Hal 9-21.

Uno, Hamzah B., \& Mohamad, N. (2014). Belajar dengan Pendekatan PAILKEM. Jakarta: Bumi

Aksara. 